\title{
A Review on Bladder Wound Healing after Mechanical Injury
}

\section{Patrik Larsson ${ }^{1}$, Clara Ibel Chamorro ${ }^{1}$ and Magdalena Fossum ${ }^{1,2 *}$}

${ }^{1}$ Department of Women's and Children's Health, Centre of Molecular Medicine, Karolinska Institutet, Stockholm, Sweden

${ }^{2}$ Department of Pediatric Surgery, Section of Urology, Astrid Lindgren Children's Hospital, Karolinska University Hospital, Stockholm, Sweden

\begin{abstract}
Congenital defects of the urinary bladder that requires surgical intervention with mechanical wounding are common situations among pediatric urology patients. In conditions with severe lack of tissue, regenerative medicine with autologous cells has become a field of interest for future cure. In both situations, normal bladder wound healing is of major importance for an uneventful healing process and for the final results. Much effort has been put into increasing our understanding in the area of urinary bladder wound healing. Several methods have been used in different studies, all representing different clinical settings to address the issue of normal healing. However, little is known about the differences between these different wound-healing models. In this review, we aimed at summarizing what is known about the process of bladder wound healing after mechanical injury. We present the most commonly used methods in this area; describe the process of healing and the current knowledge on involved signaling transduction factors.
\end{abstract}

Keywords: Wound healing; Urinary bladder; Tissue engineering; Pediatric surgery
Abbreviations
ATP: Adenosine Triphosphate; bFGF: basic Fibroblast Growth Factor, also known as FGF-2; HB-EGF: Heparin-Binding EGF-like Growth Factor; EGF: Epidermal Growth Factor; EGFR: Epidermal Growth Factor Receptor; TGF- $\alpha$ : Transforming Growth Factor-alpha; FGF-1: Fibroblast Growth Factor 1; FGF-2: Fibroblast Growth Factor 2, also known as bFGF; HGF: Hepatocyte Growth Factor; IGF-I: Insulin like Growth Factor I; IGF-receptor type I: Insulin like Factor Receptor type I; IGF-II: Insulin like Growth Factor II; KGF: Keratinocyte Growth Factor; KGFR: Keratinocyte Growth Factor Receptor; PDGF-A: Platelet Derived Growth Factor A; PDGF-B: Platelet Derived Growth Factor B; TGF- $\beta$ : Transforming Growth Factor-beta; TRPV: Transient Receptor Potential Channel; VEGF: Vascular Endothelial Growth Factor

\section{Introduction}

In pediatric urology, repairing congenital and acquired defects in the bladder and urethra can be demanding surgical procedures. Children with hypospadias, defect closure of the bladder and neurogenic bladder related to spina bifida are examples of conditions that often need urological interventions early in life and in some cases also repeatedly later in life.

Birth defects have been shown to be one of the major causes of infant death in western countries [1] and among patients admitted to specialized pediatric centers, in western countries, 12 to $50 \%$ have a congenital anomaly [2-4]. Severe anomalies in the lower urinary tract are rare when examined alone $[5,6]$ but when adding these conditions together, their common prevalence make them big contributors to morbidity and mortality. Knowledge in handling these urogenital defects is therefore crucial for surgical management and treatments in the pediatric population.

In the field of regenerative medicine, treatment strategies related to disorders in the urogenital system aim to improve tissue regeneration. This is of major importance when lack of tissue for the repair hampers conventional surgical techniques.

Research in this area aims at bringing understanding in the molecular mechanism governing bladder maintenance both during steady state and after injury.
There are several reports and reviews covering wound healing in other organs such as skin and cornea [7-9], however, to our knowledge, there are no studies covering the current knowledge on wound healing in the urinary bladder after mechanical injury. The aim of this review was to explore and summarize current knowledge in this area. In order to highlight the current common knowledge as well as identify areas that needs further investigations. We will discuss local and systemic factors that influence bladder healing and outline the similarities and differences of bladder wound healing compared to wound healing in other organs and particularly in skin wound healing.

\section{Background}

\section{Urinary bladder embryology}

The human urinary bladder is an organ consisting of a complex combination of cells of different embryological origins. The fully developed urinary bladder wall consists of different layers, including an organ specific epithelial cell layer, the urothelium, an intermediate cell layer called the lamina propria, a smooth muscle cell layer and finally a covering serosa layer also called the adventitia [10].

The development of what later becomes the human urinary bladder starts around gestational week 5 when the urogenital sinus separates into the anterior vesicourethral canal and the posterior urogenital sinus [11]. The anterior vesicourethral canal and associated allantois later becomes the bladder [11-13]. In addition, the outer layers of the urinary bladder, the lamina propria and the smooth muscle cell layer derive from mesoderm $[10,11]$.

The urothelium is a transitional epithelium [14] and has common

*Corresponding author: Magdalena Fossum, Department of Pediatric Surgery Section of Urology, Astrid Lindgren Children's hospital, Karolinska University Hospital, Stockholm, Sweden, Tel: 08-517 764 08; Fax: +46 8517708 83; E-mail: magdalena.fossum@ki.se

Received May 19, 2016; Accepted June 03, 2016; Published June 10, 2016 Citation: Larsson P, Chamorro Cl, Fossum M (2016) A Review on Bladder Wound Healing after Mechanical Injury. J Tissue Sci Eng 7: 170. doi:10.4172/21577552.1000170

Copyright: @ 2016 Larsson $\mathrm{P}$, et al. This is an open-access article distributed under the terms of the Creative Commons Attribution License, which permits unrestricted use, distribution, and reproduction in any medium, provided the original author and source are credited. 
characteristics with other epithelia, such as skin, cornea and intestine. Common features in all of these epithelial cells include that they; 1) adhere to one another via cell junctions, 2) exhibit morphologic polarity, 3) contain a basal surface with regenerative cells that are attached to an underlying basement membrane [15], and finally 4) work as a barrier to protect the internal organs from harmful substances. Historically, urothelial cells have been considered to proliferate in the basal layer [16]. However, recent research indicates that proliferation takes place also in the intermediate cell layers and mostly in the trigonum area $[17,18]$. Following mitosis, the cells then undergo a differentiation process as they reach the surface and in urothelial cells this differentiation culminates in the formation of uroplakin rich cells called umbrella cells. Uroplakins are integral proteins organized in the apical surface of the urothelium in a hexagonally packed manner and are responsible for the formation and maintenance of functional permeability barrier $[16,19]$.

Despite similarities, there are multiple differences between urothelium and other epithelia. For instance, the outermost cells are broader and have great elasticity, adjusting size according with the micturition cycle. The urothelium also have a much slower turnover rate than skin, 25 to 50 days [20-22], or the intestinal mucosa, one to three days $[23,24]$. In the urinary bladder, however, the turn-over rate of urothelial cells varies between six months up to a year $[25,26]$. In light of these differences, it seems plausible that upon wound healing, the urinary bladder reacts differently and via different pathways than other epithelium.

\section{Wound healing}

Wound healing is the process when damaged tissue is replaced with new tissue [27] and this concept include regrowth of normal tissue and scarring. The ability to react to an injury and regain acceptable function is a crucial mechanism for all multicellular mechanisms. The wound healing process is a continuous process, but in order to simplify our understanding, it is often categorized into distinct separate stages. A classical categorization, derived from wound healing studies in skin, divides healing into three main stages: Inflammation, New tissue formation and Remodeling [28-31]. Despite that some tissues do not regain original function after wounding; it is believed that the wound healing process is conserved in all organ systems $[28,32,33]$.

In 1891, Schwarz [34] reported one of the first reports on urinary bladder wound healing and tissue regeneration that described a normalsized bladder that had grown after subtotal cystectomy (STC) in dogs. Yet, despite progress since then, there are still several blind spots that need further enlightening. Today, there is not a complete description of the process of wound healing occurring in the bladder and the molecular mechanisms regulating this process are not yet fully characterized. However, studies suggest that the above-mentioned phases of wound healing also occur in the bladder. Different observations have described the processes of; inflammation, proliferation and remodeling, including production of extracellular matrix [35] and also increase of growth factors [36,37], indicating intrinsic similarities in the process in different organs [38]. As for all tissues, the healing outcome upon injury greatly depends on the magnitude of the injury. After superficial injuries, only involving the epithelium, a complete regeneration of tissue occurs without scaring while scar formation occurs if the tissue is deeply compromised [35,39].

\section{Models used for urothelial wound healing}

There are several methods to elicit wounds to the urinary bladder. The most commonly used methods to study wound healing in the urinary bladder today are mentioned in Table 1 .

It has been shown in both in vitro as well as in vivo experiments, that injuries to the mucosa (possibly into the submucosa) caused a localized injury to the mucosa whereas the underlying layers did not react in the same manner [36,39]. However, after a transmural incision, there was a response, measured as changes in the gene expression pattern; in the wounded area as well as in the bladder half that was not injured [36]. This is intriguing as this shows that the urinary bladder has the capacity of a globalized response after localized trauma but not all traumas, and it also indicates that the degree of response varies between wounds of different depths. The reason for this could be that different signaling transduction pathways are involved depending of the type of trauma. Based on this perspective, it is important to acknowledge that the chosen method should be based on the intended area to study, as this will affect the outcome.

As shown in Table 1, there are several techniques used in bladder wound healing studies. Some differences need highlighting since they focus on different processes. For instance, in vitro techniques focus specifically on urothelial cells whereas in vivo techniques include all cell types making it more difficult to discriminate which cell is responsible for each reaction. Furthermore, it needs to be emphasized in the study with partial cystectomy, the bladder increased in size, regaining some of its original size [46]; this has not been shown in other studies. Whether this increase was due to stretching per se or other cell signaling has not been investigated. In summary, all techniques complement each other but comparisons with one another are needed in order to fully understand the processes involved.

\section{Time for healing}

A relevant clinical aspect of bladder healing and postoperative care is the time it takes for the urinary bladder to heal after wounding. Several studies suggest that wound healing in the bladder occurs more rapidly than in many other tissues. Even though there is no consensus on bladder healing after surgical wounding in clinical praxis, many authors drain the bladder for 5-14 days post-surgery to minimize the risk of leakage through the incised bladder wall after open surgery.

Therefore, in order to foresee the expected time of recovery for every type of surgery the time for healing is fundamental. This can be done by measuring the time to re-epithelialization. Upon partial cystectomy the urothelial turn-over rate increased rapidly and was up-

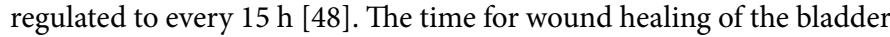

\begin{tabular}{|l|l|c|c|}
\hline \multicolumn{1}{|c|}{ Mechanism of injury } & \multicolumn{1}{c|}{ Study design } & Reference \\
\hline Scraping/scratching & Culturing of cells in vitro followed by scraping/scratching & Human, mouse & [40-43] \\
\hline Punch Biopsy & Culturing of cells in vitro followed by punch biopsy & Human & [44] \\
\hline In vivo surgery & Surgery on live animals, such as cystotomy or partial cystectomy & Rat, rabbit & [35,36,45,46] \\
\hline In vivo over inflation & $\begin{array}{l}\text { Instillation of water in live animals' bladder causing over inflation, injuring the mucosa and } \\
\text { injury to the submucosa and muscle to a lesser extent. }\end{array}$ & Mouse & [39] \\
\hline Application of a necrotizing, freeze-thaw & Local application of a necrotizing, freeze-thaw injury to the serosal surface & [47] \\
\hline
\end{tabular}

Table 1: Different methods to study wound healing after mechanical injury to the urinary bladder. References refer to articles utilizing each method. 
after different study methods is presented in Table 2. Depending on the method, the first signs of increased cell turn over appear after different time points. After over-inflation, which causes injury and disruption in the mucosa, the first signs of re-epithelialization were evident after $4 \mathrm{~h}$ [39], whereas after a transmural bladder incision, this happened after $24 \mathrm{~h} \mathrm{[36].} \mathrm{The} \mathrm{reason} \mathrm{for} \mathrm{these} \mathrm{differences} \mathrm{in} \mathrm{time} \mathrm{from} \mathrm{injury} \mathrm{to} \mathrm{start} \mathrm{of}$ re-epithelialization is likely caused by several factors.

Firstly, the studies did not use the same time points, thus the time difference might be smaller. Secondly, the two methods caused injury in different manners. An incision injures the area at the incision site, whereas over-inflation causes a globalized injury to the bladder. How this should be interpreted in combination with the data that transmural incisions cause a change in gene expression pattern also in the noninjured bladder half is not fully understood [36]. However, it is clear that there are differences between the methods.

\begin{tabular}{|l|l|c|}
\hline \multicolumn{1}{|c|}{ Days } & \multicolumn{1}{c|}{ Study design } & Reference \\
\hline $2-4$ days & Surgical wound in rat & {$[36,37,49,50]$} \\
\hline $2-5$ days & Over distension of bladder in rat & {$[39]$} \\
\hline $4-7$ days & Artificial ulceration in guinea pig & {$[49]$} \\
\hline 4 days & Cystotomy and suturing in guinea pig & {$[50]$} \\
\hline $4-10$ days & Cystotomy in rat & {$[35]$} \\
\hline
\end{tabular}

Table 2: Time for wound healing.The number of days until the urothelium heals after mechanical wounding.

\section{Proliferation}

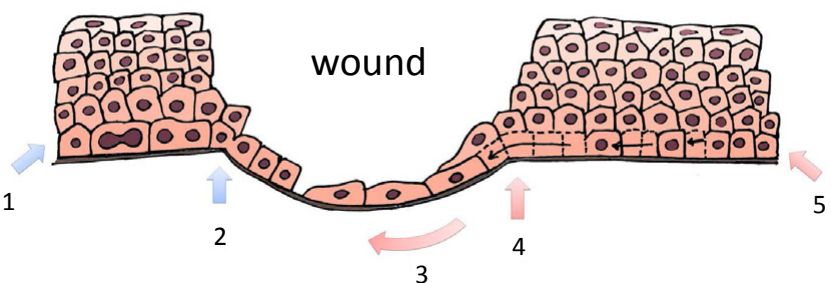

Figure 1: The role of proliferation and migration during wound healing in the urinary bladder. 1) Proliferation takes place in the basal layer [43,49], 2) Proliferation at the edge of the wound, in the peri-damaged zone $[39,43,44], 3$ ) Major coverage at the wound takes place via migration [41,51], 4) Cells closest to the wound edge migrate twice the distance compared to cells further back $[42], 5)$ Migration mostly of basal cells and not superficial [43].
The next interesting clinical measurement is the time for complete wound cover, i.e., the time until full re-epithelialization. Most in vitro and in vivo studies found that full re-epithelialization happened after $2-5$ days $[36,37,39,49,50]$. It is important to stress that this shows that from this perspective the in vitro results are representative and can be applied to the in vivo setting.

\section{Proliferation and migration}

As previously discussed, injury to the urinary bladder is followed by an upregulation of proliferation with rapid cell cycling and covering of the wound. The process involved is a combination of migration and proliferation of cells. Selections of important studies that describe the mechanisms are presented in Figure 1.

According to the studies presented, after wounding, cells start to migrate into the wound from the edges [49], and cells adjacent to the wound start to proliferate. The coverage is mainly due to migration of cells [41,51], mainly basal, cells closest to the wound edges that migrate furthest $[42,43]$. The location of proliferation depends on the depth of the wound. In in vitro models, mimicking transmural injuries, the proliferation takes place at the border of the wound [44], whereas after superficial injuries there is also a proliferation in the basal cell layer $[43,49]$. After the wound has been covered the cells starts to differentiate and within days some cells have differentiated into umbrella cells.

Several studies imply that either proliferation or migration is the most crucial contributor for healing. However, this might be more of an academic interest rather than clinically relevant. Altogether it seems likely that, from a histological point of view, the urinary bladder heals in a pattern similar to that of the skin.

\section{Signaling transduction factors}

In most tissues it has been shown that intercellular signaling peptides and proteins play a fundamental role and that some of their expressions pattern change during healing [52].

In Table 3 and Figure 2, to our knowledge, all signaling and growth factors that have been investigated after mechanical wounding of the urinary bladder urothelium are presented. It is worth noting that for many of these factors, there is only a single publication supporting their role in normal urothelial wound healing and further validation of their role is of mayor importance.

\begin{tabular}{|c|c|c|c|c|c|}
\hline Signal & Species & Tissue & Model & Effect & Reference \\
\hline Calcium & Human & Urothelial cells & In vitro, scratching & Intracellular calcium $\uparrow$ followed by cell migration & [42] \\
\hline HB-EGF & Human & Ureter urothelial & In vitro, scratching & HB-EGF mRNA $\uparrow$ & [44] \\
\hline \multirow{2}{*}{ EGFR } & Human & Ureter urothelial & In vitro, scratching & EGFR-protein $\rightarrow$ & [44] \\
\hline & Rat & Bladder & In vivo, transmural incision & EGFR mRNA $\uparrow$ in both injured and non-injured bladder half & [36] \\
\hline TGF- $\alpha$ & Rat & Bladder & In vivo, transmural incision & TGF- $\alpha$ mRNA $\uparrow$ & [36] \\
\hline FGF-1 & Mouse & Complete bladder & In vivo, over distension & FGF-1 RNA $\uparrow$ & [39] \\
\hline FGF-2 & Mouse & Complete bladder & In vivo, over distension & FGF-2 RNA $\rightarrow$ & [39] \\
\hline IGF-I & Mouse & Complete bladder & In vivo, over distension & IGF-I RNA non measurable & [39] \\
\hline IGF receptor type I & Mouse & Complete bladder & In vivo, over distension & IGFRI RNA $\uparrow 1 \mathrm{~h}$ post injury & [39] \\
\hline IGF-II & Mouse & Complete bladder & In vivo, over distension & IGF-II RNA $\uparrow 24 \mathrm{~h}$ post injury. Coincided with maximum proliferation & [39] \\
\hline KGF & Rat & Bladder & In vivo, transmural incision and pinching & KGF-mRNA $\uparrow 12 \mathrm{~h}$ post injury & [36] \\
\hline KGFR & Rat & Bladder & In vivo, transmural incision and pinching & KGFR mRNA $\rightarrow 12$ h post injury & [36] \\
\hline TGF $\beta$ & Rat & Bladder & In vivo, transmural incision and pinching & TGF $2+3$ mRNA $\rightarrow$ & {$[36]$} \\
\hline PDGF-A & Mouse & Complete bladder & In vivo, over distension & PDGF-A RNA $\rightarrow / \uparrow$ slightly & [39] \\
\hline PDGF-B & Mouse & Complete bladder & In vivo, over distension & PDGF-B RNA $\rightarrow$ & [39] \\
\hline
\end{tabular}

Table 3: Effect on expression pattern and concentration after wounding. The effect on molecular or gene expression pattern in urothelium after wounding. 


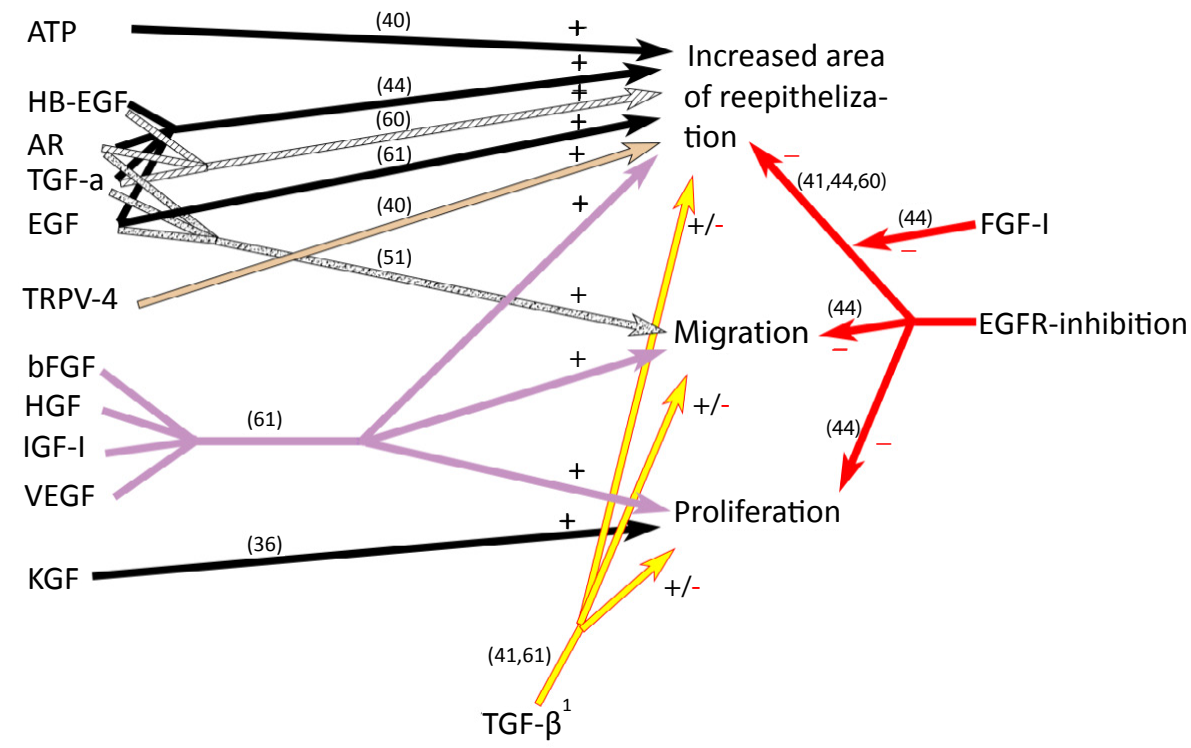

Figure 2: A summary of the effects of different factors known to affect bladder wound healing. Increased area of re-epithelization: Remaining non-covered area at the end of the experiment compared to non-covered area in the beginning of the experiment.

Numbers in brackets indicate reference number $+=$ stimulation, $-=$ inhibition, ${ }^{1}=$ TGF- $\beta$ has shown different effects on differentiated and non-differentiated urothelial cells.

\section{ATP}

Adenosine triphosphate (ATP), classically considered being a reservoir of energy [53] has been shown to do much more, including acting as a transmission factor. Upon wounding of the cornea, there is a release of ATP and this affect the EGFR signaling, positively affecting wound healing [54]. It has been shown that ATP is one of the key signaling factors in some urothelial diseases [55]. Therefore, as seen in Figure 2, the finding that addition of ATP increased wound healing in urothelium [40] support the notion that ATP play a role in wound healing and that the urothelium reacts similarly as other epithelium such as the cornea.

\section{Calcium}

Calcium seems to play an important role as an early and immediate damage signal as well as an up-regulator of gene expression [56] in both in vitro and in vivo models.

Upon wounding, the intracellular concentration of calcium increased (Table 3) within seconds [42]. In addition, the wounding induced a release of calcium extracellularly that started at the cells at the wound edge which lead to a wave of calcium, partly mediated via ATP, that spread out from the wound. Previous studies in cornea support the finding that the calcium wave might be mediated via ATP $[57,58]$. However, the function of these findings in urothelial in vivo models still needs to be explored.

\section{EGF}

Some of the most extensively studied growth factors in wound healing are the epidermal growth factor (EGF)-family. This family consist of several factors, amongst others epidermal growth factor (EGF), heparin-biding EGF (HB-EGF), transforming growth factor- $a$ (TGF- $\alpha$ ), epiregulin, amphiregulin, betacellulin, epigen and neuregulins 1-6 [7]. The EGF-ligands bind to epidermal growth factor receptor (EGFR) [51,59] with an extensive signaling pathway.

The effect of EGF on healing of injured urothelium has been studied by several groups, as seen in Table 3 and Figure 2. In human ureter urothelium HB-EGF mRNA increased upon wounding but there was no change in the expression of AR or TGF- $\alpha$ [44]. However, treatment with TGF- $\alpha$, EGF [51], HB-EGF, AR [44,60] and EGF increased the regenerated area [44] (Figure 2). Urothelium from the bladder react similarly, EGF, TGF- $\alpha$, and to a lesser degree amphiregulin, stimulated wound closure, mainly via migration [51] and the area of re-epithelization [60] as well as proliferation [61]. Moreover inhibition of EGFR-signaling inhibited wound closure [60] and delayed the wound healing in both differentiated and non-differentiated bladder urothelium [41], as well as decreased proliferation and migration in ureter urothelium [44]. These findings are also in line with work in other tissue, such as the cornea where injury leads to an activation of EFGFR which is crucial for cell migration [54]. Moreover, it has been shown in skin, that after a partial thickness wound, EGF have a steady concentration in wound fluid and the wound healing accelerate after exogenous EGF-administration [62]. These similarities indicate that the urothelium have a similar response as other epithelia.

\section{FGF}

Fibroblastic growth factors (FGFs) are a family of growth factors which in vertebrates constitutes of 22 different members [63] including fibroblast growth factor 1 (FGF1) and FGF-2, also known as bFGF [64]. Both FGF1 and 2 have been shown to be released within wounds and stimulate fibroblast and keratinocyte proliferation and migration. They have also been shown to promote endothelial migration during the early phase of wound healing [65] and application of FGF-2 on skin accelerate the rate of epithelialization [66]. As shown in Table 3, FGF-1 RNA expression increased after mechanical wounding whereas FGF-2 did not change [39]. The reason for this difference in FGF-2 expression pattern as compared to skin is not known. As for exogenous FGF treatment (Figure 2) the effect on cells treated with AG1478, a tyrosine kinase inhibitor that inhibits proliferation and migration was partially reversed when co-treated with FGF-1 [44]. These findings indicate that FGF-1 treatment promote wound healing, however, since there are no results on the effect without the inhibitor the direct effects of FGF-1 
treatment are still unclear. Exogenous treatment with bFGF(FGF-2) (Figure 2) promote proliferation, migration and increase the area of reepithelization [61], which is a similar reaction as that in skin. These results, however, have not yet been validated.

\section{KGF}

Keratinocyte growth factor (KGF), is a member of the FGF family, consisting of KGF-1, also known as FGF7, and KGF2, known as FGF10 [66] and both are known mitogenic factors on epithelialization. Moreover, the expression of KGF increase shortly after wounding in skin [67], and KGF-1 and KGF-2 administration increase wound strength and the collagen contents. In cornea, treatment with KGF increases the proliferation [68].

Table 3 shows that after wounding, the KGF mRNA increased [36]. Moreover, exogenous treatment with KGF increased the proliferation (Figure 2) with the most profound increase in the basal layers of the urothelium [36], indicating that exogenous treatment augments the natural reaction after wounding. The expression of KGFR did not change upon wounding (Table 3). This is in contrast to mechanical wounding in other organs, such as skin, in which KGFR is upregulated $[69,70]$. The reason for these differences is not fully understood.

\section{TGF}

Transforming growth factors (TGF) is a superfamily with at least 30 different growth factors of which some are the TGF- $\beta 1-3$ [71]. During wound healing the TGF- $\beta$ s have been shown to be increased in wound fluid $[31,62]$, stimulate extracellular matrix production via inhibition of the degrading enzymes as well as stimulate fibroblast and leukocyte migration [72]. Treatment with TGF- $\beta 1$ increases the granulation tissue, re-epithelialization [73] and stimulates angiogenesis [65].

A seen in Table 3, there was no change in the expression pattern of either TGF- $\beta 2$ or 3 after wounding [36]. It should be noted that this is a discrepancy compared to the reaction in skin $[74,75]$, and this could indicate a different effect of TGF- $\beta$ on urothelium than on skin. Exogenous treatment with TGF- $\beta$ on neurogenic bladder urothelium (Figure 2) inhibits proliferation, migration and wound healing [61]. However, in another study, it was shown that TGF- $\beta$-treatment led to a delayed wound healing in non-differentiated urothelium whereas differentiated cells had an accelerated healing [41] and that blocking of TGF- $\beta$ signaling led to a smaller area of re-epithelization in differentiated cells but no difference in non-differentiated. These somewhat contradicting results in differentiated and non-differentiated cells could strengthen the hypothesis that there is a difference in effect of TGF- $\beta$ on skin versus urothelium. These differences in responses suggest dissimilarity in action; however, the clinical significance remains unclear. Interestingly, in skin, it has been proven that the three TGF- $\beta$ isoforms have different effects on wound healing; TGF- $\beta 1$ and 2 promote scarring whereas TGF- $\beta 3$ might actually prevent scarring [66]. If this is valid for urothelial wound healing needs further investigation.

\section{PDGF}

Platelet derived growth factor (PDGF) is a group of dimeric disulfide-bond growth factors [76] with mostly a paracrine action [77]. PDGF has been shown to be chemotactic for cells migrating into wounds and to stimulate fibroblast proliferation and ECM production [31]. In skin wound-healing models, exogenous administration of PDGF accelerated wound healing [62,78].

Table 3 demonstrates that PDGF A and B have a high constitutive expression and after wounding the expression only tended to increase
[39]. In a recent comprehensive review on the subject, evidence is presented that PDGFs are constitutively expressed rather than due to regulation [77]. This could support the finding that the PDGFs did not show any major change in expression in urothelium. However, further validation is needed.

\section{HGF}

Hepatocyte growth factor, also known as scatter factor (HGF/SF) is a growth factor with effects on cell migration and proliferation during embryogenesis as well as having a protective role in some diseases and also influencing the development of some cancers $[79,80]$. HGF/ SF acts via signaling to the c-MET receptor that in turn influences the above mentioned processes. HGF/SF is secreted mostly via fibroblasts and mesenchymal cells whereas the c-MET receptor is predominantly expressed by cells of epithelial origin [81]. The expression level of HGF/ SF as well as c-Met receptor has been shown to be upregulated in some disease, such as liver, kidney and heart injury, both in plasma and in the affected organ $[79,82]$ and exogenous treatment with HGF prior to injury has a protective effect $[83,84]$. Moreover, HGF positively affect wound healing in epithelia $[85,86]$. HGF treatment after mechanical injury to urothelium (Figure 2) increase the proliferation and migration of urothelial cells as well as the area of reepithelization after wounding [61]. This indicates that the urothelium react to HGF similarly as other epithelial cells do. However, the effect of wounding on the expression level in urothelium has yet to be studied.

\section{IGF}

Insulin like growth factors (IGF) is a family of proteins consisting of IGF-I and II [87], of which IGF-II is most prominently expressed in fetal tissue whereas IGF-I is expressed even in adult tissue [88]. IGF-I am mitogenic for several cell types, such as fibroblasts and keratinocytes [89] and has been shown to be able to act on a local (autocrine and paracrine) and a systemic level.

In skin, the level of IGF-I increase in the wounded epidermis after injury [90] whereas exogenous treatment has shown varying responses and mono-treatment with IGF seems to have no effect on wound healing in skin $[91,92]$. However, co-treatment with IGF-I and IGF binding proteins enhance wound healing [91]. Moreover, co-treatment with IGF and TGF- $\beta$ reversed the decrease in epithelial thickness that TGF- $\beta$ has alone [92].

Therefore, as shown in Table 3, the finding that there was no change in the RNA-expression of IGF-I after over distension of the urinary bladder [39] indicate that the there is no change in the expression of IGF-I in injured and non-injured urothelium. Somewhat contradictory, in another study, exogenous treatment with IGF-1 (Figure 2) promoted proliferation, migration and increased area of re-epithelization [61]. However, whether these findings and differences, in comparison to skin, are true needs further validation. As for IGF-II and IGF-receptor 1 , there was a stable expression has been described after global injury that increased $24 \mathrm{~h}$ after [39] and coincided with re-epithelialization and maximal urothelial proliferation.

\section{TRPV}

The transient receptor potential channel (TRP) group is a family of 6 trans-membrane cation-permeable channels consisting of six subfamilies, one of which is TRPV [93]. The TRP channels mediate flux of cations, such as calcium and sodium, leading to cell depolarization. The TRPV-subgroup consists of TRPV1-6, of which 1-4 are all activated by heat $[93,94]$. The expression of TRPV is still not fully understood 
but there are reports that some of the TRPV-channels are expressed in the urinary bladder possibly having an effect on wound healing [9396]. TRPV1 has been shown to mediate wound healing in cornea [97]. Moreover, it is known that there is a cross-activation of TRPV1 via the TGF- $\beta$ pathway [98]. TRPV4 play a role in pain sensation [94], however little is known of its role of TRPV4 in wound healing.

Exogenous treatment with TRPV1 agonist or antagonist had no effect on rate of scratch repair whereas a TRPV4 agonist (Figure 2) increased the rate of scratch repair in a dose dependent manner [40]. However antagonist did not reverse effect [40]. Since the role of TRPVreceptors in wound healing in other tissues still not is fully understood, it is still unclear how these findings should be fully interpreted and this area needs further studying.

\section{VEGF}

Vascular endothelial growth factor (VEGF) is a signaling factor, structurally similar to PDGF, with two different receptors; VEGFR1 and 2 [99] and VEGF co-receptors: NRP 1 and 2. VEGF has multiple roles both during embryogenesis as well as in adult tissues when it is partially responsible for vessel homeostasis as well as vascular branching [100]. Upon wounding, VEGF is secreted and stimulate angiogenesis, via stimulation of endothelial cells that in turn stimulate proliferation, basal membrane degradation, vasodilation and chemotaxis [101]. In skin wound healing, the expression of VEGF has been shown to increase the first 2-5 days post injury [101,102]. Exogenous treatment with VEGF on urothelial wounds after mechanical injury (Figure 2) increase the proliferation and migration of urothelial cells [61]. This implies that the urothelium react to VEGF similarly as epithelial cells in the skin. The effect of wounding on the expression level has yet to be studied.

Besides the reported results in Table 3 and Figure 2 there are some additional findings worth mentioning; some signaling transduction molecules were not found upon wounding, for instance, after wounding there was not RNA expression of IGFBP-1,3,4,5 or 6 in the urinary bladder, nor for the PDGF-receptor [39].

\section{Discussion}

Wound healing is a fundamental process for all multicellular organisms as adaption to changes in the environment and injuries is crucial for survival. However, different organisms solve this differently (e.g. amphibians [103] and plants [104]) and the healing modalities vary in different tissues within the same species.

As discussed in this review, when analyzing and extrapolating the results from previous studies it is important to highlight the differences in methodology. Since there are no studies comparing the different wound healing models, generalizing the results from one model to the other should be done with care. We only assume that the methods elicit similar changes. This assumption seems plausible, but still has to be proven. As we have discussed, it has been shown in some species that the urinary bladder adapts to regain some of its original size after subtotal cystectomy $[46,105]$ and since this relative increase in bladder size has not been shown in other models, this indicates that molecular signaling is involved that is unique for the model of wounding. As authors we therefore ask for and encourage studies comparing different wound healing models.

In this review, we chose to exclude studies focusing on chemical injuries, i.e. global injuries using chemical solutions as there are no studies comparing mechanical injury to other conditions with bladder inflammation such as; interstitial, infectious or chemical cystitis, induced by agents such as cytostatic agents, in the urinary bladder. If the healing mechanisms in these conditions would be the same as after mechanical wounding one could apply much knowledge and improve our understanding in wound healing after mechanical injury significantly.

The findings in this review strengthen the idea that the urinary bladder heals in a pattern similar to that of the other epithelia, such as the skin. The healing pattern with proliferation in the peri-damaged area and also the basal layer, after superficial wounding, follows the same path as in the skin. However, during the classical healing pattern involving inflammation, new tissue formation and remodeling, in skin, the inflammatory phase includes infiltration of inflammatory cells such as macrophages and neutrophils [106]. The immune cells are responsible for the secretion of several signal transduction factors that attract other cells as well affect the healing of the wound in skin. This involvement of inflammatory cells has not, however, been shown in the urinary bladder. Whether this represents a difference between skin and urinary bladder or just is an area not yet fully understood needs further investigation.

As was mentioned in the introduction, congenital defects are major contributors to infant morbidity. The field of regenerative medicine and tissue engineering is a promising area aiming at regenerating damaged or absent tissues and organs [107]. In pediatric urology, tissue engineering has been mostly integrated in clinical settings in urethral defects with good results [108-110]. However, some urinary bladder defects, such as bladder exstrophy or small neuropathic bladders, can be challenging to treat. A breakthrough for tissue engineering of the bladder was the study by Atala et al. [111] where the authors found that autologous cells seeded on a carrier material could be integrated in the bladder for bladder expansion in patients with myelomeningocele. However, there are still several questions that need answering before bladders can be engineered in the clinical setting.

In this review we have summarized the current knowledge of the effect of growth factors on wound healing in the bladder. Interestingly, the effect of some of these growth factors has also been investigated in tissue engineering. Using scaffolds of extracellular matrix has been shown as alternatives to regain function of the urinary bladder [112114]. Incorporating growth factors in these scaffolds is a promising area of research to improve speed to a functional bladder and among investigated growth factors are VEGF, bFGF, NGF and PDGF-BB. Most studies on the urinary bladder have focused on VEGF as some propose that vascularization is the limiting step for a functional bladder. Incorporating VEGF has been shown to increase angiogenesis, increase muscle regeneration and affect urothelial ingrowth [115-119]. However, its effect on the urothelium per se in these tissue engineering studies is still not fully understood $[115,116,118,120]$. VEGF stimulate the speed to gain a functional urothelium in tissue engineering studies. However, the effect on urothelium seem to be less prominent than that on smooth muscle cells and vascularization and this lesser effect could possibly be due to the mechanism of action of VEGF, i.e. induction of different pathways in different cell types, but also on the fact that most studies have had the first endpoints at 4 weeks, at which time the effect on urothelium in wound healing models has passed.

It has been shown in some tissue engineering studies that following patching after a partial cystectomy, epithelialization of bladder patches took place after 4 days [121] and lining of the luminal surface was complete 2 weeks after surgery $[112,122]$, a time span similar to healing after mechanical wounding as presented in Table 2. This shows that there are similarities in the early stages of wound healing and tissue 
regeneration of the bladder via surgically patching of matrix to bladders after subtotal cystectomy. Unfortunately, as there are few studies in bladder tissue engineering focusing on earlier time points, there is not much data on the effect of the treatment on the urothelium in the early phases after attachments. Moreover, as shown in Figure 1 the major coverage of a wound is dependent on both proliferation and migration. However, in tissue engineering studies, there are those that claim that the source of urothelial regeneration in these models is due to migration of adjacent viable bladder cells $[120,121]$. However, the extent of the contribution of proliferation has yet to be investigated. Therefore, concluding whether there are any differences between urothelial wound healing and the growth of urothelium in tissue engineered matrixes is not possible.

\section{Conclusion}

There are major gaps of knowledge in our understanding of bladder wound healing; the study of wound healing processes occurring in internal organs are not as straight forward to study as in the skin or other more accessible organs. In the numerous articles addressing wound healing in the urinary bladder, the lack of uniformity lead to few validated studies and an inability to compare studies with each other. Only a few studies are dedicated to the topic of bladder wound healing in a thoroughly manner, however, it is possible to conclude that the processes of bladder wound healing resembles the events that occur in the skin, by activating in a continuous fashion; inflammation, proliferation, and, finally tissue-remodeling through the production of collagen and extracellular matrix proteins. Growth factors, especially those from the EGF family play an important role in controlling proliferation and migration as has been described by both in vitro and in vivo studies.

\section{Acknowledgement}

The authors want to than Virginia Amesty, MD, for her artistic support. Grants from the Promobilia Foundation, the Swedish Society for Medical Research, the Crown Princess Lovisa Foundation, the Freemason Foundation for Children's Welfare, the Stockholm City Council and the Swedish Society of Medicine supported this work.

\section{References}

1. Centers for Disease Control and Prevention (CDC) (1996) Infant mortalityUnited States, 1993. MMWR Morb Mortal Wkly Rep 45: 211-215.

2. Yoon PW, Olney RS, Khoury MJ, Sappenfield WM, Chavez GF, et al. (1997) Contribution of birth defects and genetic diseases to pediatric hospitalizations. A population-based study. Arch Pediatr Adolesc Med 151: 1096-1103.

3. O'Malley M, Hutcheon RG (2007) Genetic disorders and congenital malformations in pediatric long-term care. J Am Med Dir Assoc 8: 332-334

4. Hall JG, Powers EK, Mcllvaine RT, Ean VH (1978) The frequency and financial burden of genetic disease in a pediatric hospital. Am J Med Genet 1: 417-436.

5. Siffel C, Correa A, Amar E, Bakker MK, Bermejo-Sánchez E, et al. (2011) Bladder exstrophy: An epidemiologic study from the international clearing house for birth defects surveillance and research, and an overview of the literature. Am J Med Genet C Semin Med Genet 4: 321-322.

6. Versteegh HP, van Rooij IA, Levitt MA, Sloots CE, Wijnen RM, et al. (2013) Longterm follow-up of functional outcome in patients with a cloacal malformation: A systematic review. J Pediatr Surg 48: 2343-2350.

7. Barrientos S, Stojadinovic O, Golinko MS, Brem H, Tomic-Canic M (2008) Growth factors and cytokines in wound healing. Wound Repair Regen 16: 585601.

8. Lu L, Reinach PS, Kao WW (2001) Corneal epithelial wound healing. Exp Biol Med (Maywood) 226: 653-664.

9. Reinke JM, Sorg H (2012) Wound repair and regeneration. Eur Surg Res 49: 35-43.
10. DeSouza, KR, Saha M, Carpenter AR, Scott M, McHugh KM (2013) Analysis of the Sonic Hedgehog signaling pathway in normal and abnormal bladder development. PLoS One 8: e53675.

11. Rasouly HM, Lu W (2013) Lower urinary tract development and disease. Wiley Interdiscip Rev Syst Biol Med 5: 307-342.

12. DiSandro MJ, Li Y, Baskin LS, Hayward S, Cunha G (1998) Mesenchymalepithelial interactions in bladder smooth muscle development: Epithelial specificity. J Urol 160: 1040-1046.

13. Staack A, Hayward SW, Baskin LS, Cunha GR (2005) Molecular, cellular and developmental biology of urothelium as a basis of bladder regeneration. Differentiation 73: 121-133

14. Yamany T, Van Batavia J, Mendelsohn C (2014) Formation and regeneration of the urothelium. Curr Opin Organ Transplant 19: 323-330.

15. Ross MH, Pawlina W (2006) Histology: a text and atlas: with correlated cell and molecular biology. Lippincott Williams \& Wilkins, Philadelphia.

16. Sun TT (2006) Altered phenotype of cultured urothelial and other stratified epithelial cells: implications for wound healing. Am J Physiol Renal Physiol 291: F9-21.

17. Sun W, Wilhelmina Aalders T, Oosterwijk E (2014) Identification of potentia bladder progenitor cells in the trigone. Dev Biol 393: 84-92.

18. Gandhi D, Molotkov A, Batourina E, Schneider K, Dan H, et al. (2013) Retinoid signaling in progenitors controls specification and regeneration of the urothelium. Dev Cell 26: 469-482.

19. Bolland F, Southgate $\mathrm{J}$ (2008) Bio-engineering urothelial cells for bladder tissue transplant. Expert Opin Biol Ther 8: 1039-1049.

20. Koster MI (2009) Making an epidermis. Ann N Y Acad Sci 1170: 7-10.

21. Weinstein GD, McCullough JL, Ross $P$ (1984) Cell proliferation in normal epidermis. J Invest Dermatol 82: 623-628.

22. Reddy MB, Guy RH, Bunge AL (2000) Does epidermal turnover reduces percutaneous penetration? Pharm Res 17: 1414-1419.

23. Creamer B, Shorter RG, Bamforth J (1961) The turnover and shedding of epithelial cells. I. The turnover in the gastro-intestinal tract. Gut 2: 110-118.

24. Potten CS (1998) Stem cells in gastrointestinal epithelium: Numbers, characteristics and death. Philos Trans R Soc Lond B Biol Sci 353: 821-830.

25. Baskin LS, Hayward SW, Sutherland RA, DiSandro MS, Thomson AA, et al (1997) Cellular signaling in the bladder. Front Biosci 2: d592-595.

26. Hicks RM (1975) The mammalian urinary bladder: An accommodating organ Biol Rev Camb Philos Soc 50: 215-246.

27. Sun BK, Siprashvili Z, Khavari PA (2014) Advances in skin grafting and treatment of cutaneous wounds. Science 346: 941-945

28. Gurtner GC, Werner S, Barrandon Y, Longaker MT (2008) Wound repair and regeneration. Nature 453: 314-321.

29. Reish RG, Eriksson E (2008) Scars: A review of emerging and currently available therapies. Plast Reconstr Surg 122: 1068-1078.

30. Singer AJ, Clark RA (1999) Cutaneous wound healing. N Engl J Med 341: 738 746.

31. Werner S, Grose R (2003) Regulation of wound healing by growth factors and cytokines. Physiol Rev 83: 835-870.

32. Biedermann T, Boettcher-Haberzeth S, Reichmann E (2013) Tissue engineering of skin for wound coverage. Eur J Pediatr Surg 23: 375-382.

33. Seifert AW, Maden M (2014) New insights into vertebrate skin regeneration. Int Rev Cell Mol Biol 310: 129-169.

34. Schwarz R (1891) Ricerche in proposito della rigenerazione della vescica urinaria. Sperimentale 45: 484.

35. Bilbao M, Spaniol A, Bearss J, Schellhase C, Shippey S, et al. (2014) Histology surrounding cystotomy healing in a Sprague-Dawley rat model. International urogynecology journal 25: 97-101.

36. Baskin LS, Sutherland RS, Thomson AA, Nguyen HT, Morgan DM, et al. (1997) Growth factors in bladder wound healing. J Urol 157: 2388-2395.

37. Wishnow KI, Johnson DE, Grignon DJ, Cromeens DM, Ayala AG (1989) 
Regeneration of the canine urinary bladder mucosa after complete surgical denudation. J Urol 141: 1476-1479.

38. Yannas IV (2015) Tissue and organ regeneration in adults: extension of the paradigm to several organs. (2ndedn), Springer, New York, USA.

39. de Boer WI, Schuller AG, Vermey M, van der Kwast TH (1994) Expression of growth factors and receptors during specific phases in regenerating urothelium after acute injury in vivo. Am J Pathol 145: 1199-1207.

40. Shabir S, Cross W, Kirkwood LA, Pearson JF, Appleby PA, et al. (2013) Functional expression of purinergic P2 receptors and transient receptor potential channels by the human urothelium. American journal of physiology Renal physiology 305: F396-406.

41. Fleming JM, Shabir S, Varley CL, Kirkwood LA, White A, et al. (2012) Differentiation-associated reprogramming of the transforming growth factor $ß$ receptor pathway establishes the circuitry for epithelial autocrine/paracrine repair. PLoS One 7: e51404.

42. Shabir S, Southgate J (2008) Calcium signalling in wound-responsive normal human urothelial cell monolayers. Cell Calcium 44: 453-464.

43. Kreft ME, Sterle M, Veranic P, Jezernik, K (2005) Urothelial injuries and the early wound healing response: tight junctions and urothelial cytodifferentiation. Histochem Cell Biol 123: 529-539.

44. Daher A, de Boer WI, El-Marjou A, van der Kwast T, Abbou CC, et al. (2003) Epidermal growth factor receptor regulates normal urothelial regeneration. Lab Invest 83: 1333-1341.

45. Machado C, Chin EW, loshii SO, Tâmbara Filho R, Von Bathen A (2007) Influence of nicotine on healing of vesical sutures in rabbits. Acta Cir Bras 22: 479-484.

46. Burmeister D, Aboushwareb T, Tan J, Link K, Andersson KE, et al. (2010) Early stages of in situ bladder regeneration in a rodent model. Tissue Eng Part A 16: 2541-2551.

47. Faggian L, Pampinella F, Roelofs M, Paulon T, Franch R, et al. (1998) Phenotypic changes in the regenerating rabbit bladder muscle. Role of interstitial cells and innervation on smooth muscle cell differentiation. Histochem Cell Biol 109: 2539.

48. Kunze E, Wöltjen HH, Nehm FJ, Schauer A (1981) Cell cycle kinetics of regenerating urothelial cells of the rat urinary bladder after partial cystectomy. Virchows Arch B Cell Pathol Incl Mol Pathol 38: 117-125.

49. Wong YC, Martin BF (1977) A study of light and scanning electron microscopy of the lining epithelium of the guinea pig bladder following artificial ulceration. Am J Anat 150: 219-235.

50. Hepperlen TW, Stinson W, Hutson J, Bartone FF (1975) Epithelialization after cystotomy. Invest Urol 12: 269-271.

51. Bindels EM, van der Kwast TH, Izadifar V, Chopin DK, de Boer WI (2002) Functions of epidermal growth factor-like growth factors during human urothelial re-epithelialization in vitro and the role of erbB2. Urol Res 30: 240-247.

52. Kiwanuka E, Junker J, Eriksson E (2012) Harnessing growth factors to influence wound healing. Clin Plast Surg 39: 239-248.

53. Khakh BS, Burnstock G (2009) The double life of ATP. Sci Am 301: 84-90, 92.

54. Yin J, Xu K, Zhang J, Kumar A, Yu FS (2007) Wound-induced ATP release and EGF receptor activation in epithelial cells. J Cell Sci 120: 815-825.

55. Winder M, Tobin G, ZupanÄ $\square i \ddot{A} \square D$, Romih R (2014) Signalling molecules in the urothelium. Biomed Res Int 2014: 297295

56. Cordeiro JV, Jacinto A (2013) The role of transcription-independent damage signals in the initiation of epithelial wound healing. Nat Rev Mol Cell Biol 14: 249-262.

57. Klepeis VE, Cornell-Bell A, Trinkaus-Randall V (2001) Growth factors but not gap junctions play a role in injury-induced $\mathrm{Ca}^{2+}$ waves in epithelial cells. $\mathrm{J}$ Cell Sci 114: 4185-4195.

58. Chifflet S, Justet, C, Hernández JA, Nin V, Escande C, et al. (2012) Early and late calcium waves during wound healing in corneal endothelial cells. Wound Repair Regen 20, 28-37.

59. Mitsudomi T, Yatabe $Y(2010)$ Epidermal growth factor receptor in relation to tumor development: EGFR gene and cancer. FEBS J 277: 301-308.

60. Varley C, Hill G, Pellegrin S, Shaw NJ, Selby PJ, et al. (2005) Autocrine regulation of human urothelial cell proliferation and migration during regenerative responses in vitro. Exp Cell Res 306: 216-229.

61. Yang B, Zhou L, Peng B, Sun Z, Dai Y, et al. (2014) In vitro comparative evaluation of recombinant growth factors for tissue engineering of bladder in patients with neurogenic bladder. J Surg Res 186: 63-72.

62. Breuing K, Andree C, Helo G, Slama J, Liu PY, et al. (1997) Growth factors in the repair of partial thickness porcine skin wounds. Plast Reconstr Surg 100 657-664.

63. Itoh N, Ornitz DM (2011) Fibroblast growth factors: From molecular evolution to roles in development, metabolism and disease. J Biochem 149: 121-130.

64. Li PF, Zhou ZL, Shi CY, Hou JF (2015) Down regulation of basic fibroblast growth factor is associated with femoral head necrosis in broilers. Poult Sci 94: $1052-1059$.

65. Li J, Zhang YP, Kirsner RS (2003) Angiogenesis in wound repair: Angiogenic growth factors and the extracellular matrix. Microsc Res Tech 60: 107-114.

66. Rumalla VK, Borah GL (2001) Cytokines, growth factors and plastic surgery Plast Reconstr Surg 108: 719-733.

67. Xia YP, Zhao Y, Marcus J, Jimenez PA, Ruben SM, et al. (1999) Effects of keratinocyte growth factor-2 (KGF-2) on wound healing in an ischaemiaimpaired rabbit ear model and on scar formation. J Pathol 188: 431-438.

68. Yu FS, Yin J, Xu K, Huang J (2010) Growth factors and corneal epithelial wound healing. Brain Res Bull 81: 229-235

69. Li M, Firth JD, Putnins EE (2009) An in vitro analysis of mechanical woundinginduced ligand-independent KGFR activation. J Dermatol Sci 53: 182-191.

70. Firth JD, Putnins EE (2004) Keratinocyte growth factor 1 inhibits wound edge epithelial cell apoptosis in vitro. J Invest Dermatol 122: 222-231.

71. Gordon KJ, Blobe GC (2008) Role of transforming growth factor-beta superfamily signaling pathways in human disease. Biochim Biophys Acta 1782 197-228.

72. Efron PA, Moldawer LL (2004) Cytokines and wound healing: The role of cytokine and anticytokine therapy in the repair response. J Burn Care Rehabil 25: $149-160$.

73. Mustoe TA, Pierce GF, Morishima C, Deuel TF (1991) Growth factor-induced acceleration of tissue repair through direct and inductive activities in a rabbit dermal ulcer model. J Clin Invest 87: 694-703.

74. Ramirez H, Patel SB, Pastar I (2014) The role of TGF $\left.\right|^{2}$ signaling in wound epithelialization. Adv Wound Care (New Rochelle) 3: 482-491.

75. Cox DA, Kunz S, Cerletti N, McMaster GK, Burk RR (1992) Wound healing in aged animals--effects of locally applied transforming growth factor beta 2 in different model systems. EXS 61: 287-295.

76. Alvarez RH, Kantarjian HM, Cortes JE (2006) Biology of platelet-derived growth factor and its involvement in disease. Mayo Clin Proc 81: 1241-1257.

77. Andrae J, Gallini R, Betsholtz C (2008) Role of platelet-derived growth factors in physiology and medicine. Genes Dev 22: 1276-1312.

78. Pierce GF, Tarpley JE, Yanagihara D, Mustoe TA, Fox GM, et al. (1992) Plateletderived growth factor (BB homodimer), transforming growth factor-beta 1 and basic fibroblast growth factor in dermal wound healing. Neovessel and matrix formation and cessation of repair. Am J Pathol 140: 1375-1388.

79. Birchmeier C, Birchmeier W, Gherardi E, Vande Woude GF (2003) Met, metastasis, motility and more. Nat Rev Mol Cell Biol 4: 915-925.

80. Organ SL, Tsao MS (2011) An overview of the c-MET signaling pathway. Ther Adv Med Oncol 3: S7-7S19.

81. Furge KA, Zhang YW, Vande Woude GF (2000) Met receptor tyrosine kinase: Enhanced signaling through adapter proteins. Oncogene 19: 5582-5589.

82. Rabkin R, Fervenza F, Tsao T, Sibley R, Friedlaender M, et al. (2001) Hepatocyte growth factor receptor in acute tubular necrosis. J Am Soc Nephrol 12: $531-540$.

83. Nakamura T, Mizuno S, Matsumoto K, Sawa Y, Matsuda H, et al. (2000) Myocardial protection from ischemia/reperfusion injury by endogenous and exogenous HGF. J Clin Invest 106: 1511-1519.

84. Stewart N, Chade AR (2013) Renoprotective effects of hepatocyte growth factor in the stenotic kidney. Am J Physiol Renal Physiol 304: F625-633. 
Citation: Larsson P, Chamorro Cl, Fossum M (2016) A Review on Bladder Wound Healing after Mechanical Injury. J Tissue Sci Eng 7: 170. doi:10.4172/2157-7552.1000170

85. Li JF, Duan HF, Wu CT, Zhang DJ, Deng Y, et al. (2013) HGF accelerates wound healing by promoting the dedifferentiation of epidermal cells through ß1-integrin/ILK pathway. Biomed Res Int 2013: 470418-470427.

86. D'Angelo F, Bernasconi E, Schäfer M, Moyat M, Michetti P, et al. (2013) Macrophages promote epithelial repair through hepatocyte growth factor secretion. Clin Exp Immunol 174: 60-72.

87. LeRoith D, Roberts CT Jr (2003) The insulin-like growth factor system and cancer. Cancer Lett 195: 127-137.

88. Bennett NT, Schultz GS (1993) Growth factors and wound healing: Biochemical properties of growth factors and their receptors. Am J Surg 165: 728-737.

89. Hsu C, Chang J (2004) Clinical implications of growth factors in flexor tendon wound healing. J Hand Surg Am 29: 551-563.

90. TodoroviÄ $\ddagger$, Pesko P, Micev M, BjeloviÄ $¥$ M, Budec M, et al. (2008) Insulinlike growth factor-I in wound healing of rat skin. Regul Pept 150: 7-13.

91. Zhao LL, Galiano RD, Cox GN, Roth SI, Mustoe TA (1995) Effects of insulinlike growth factor-I and insulin-like growth factor binding protein-1 on wound healing in a dermal ulcer model. Wound Repair Regen 3: 316-321.

92. Lynch SE, Colvin RB, Antoniades HN (1989) Growth factors in wound healing Single and synergistic effects on partial thickness porcine skin wounds. J Clin Invest 84: 640-646.

93. Ramsey IS, Delling M, Clapham DE (2006) An introduction to TRP channels. Annu Rev Physiol 68: 619-647.

94. Nilius B, Owsianik G, Voets T, Peters JA (2007) Transient receptor potential cation channels in disease. Physiol Rev 87: 165-217.

95. Earley S, Brayden JE1 (2015) Transient receptor potential channels in the vasculature. Physiol Rev 95: 645-690.

96. Avelino A, Charrua A, Frias B, Cruz C, Boudes M, et al. (2013) Transient receptor potential channels in bladder function. Acta Physiol (Oxf) 207: 110122

97. Sumioka T, Okada Y, Reinach PS, Shirai K, Miyajima M, et al. (2014) Impairment of corneal epithelial wound healing in a TRPV1-deficient mouse. Invest Ophthalmol Vis Sci 55: 3295-3302.

98. Mergler S, Valtink M, Takayoshi S, Okada Y, Miyajima M (2014) Temperaturesensitive transient receptor potential channels in corneal tissue layers and cells. Ophthalmic Res 52: 151-159.

99. Ferrara N, Gerber HP, LeCouter J (2003) The biology of VEGF and its receptors. Nat Med 9: 669-676.

100. Carmeliet P, Jain RK (2011) Molecular mechanisms and clinical applications of angiogenesis. Nature 473: 298-307.

101.Bao P, Kodra A, Tomic-Canic M, Golinko MS, Ehrlich HP, et al. (2009) The role of vascular endothelial growth factor in wound healing. J Surg Res 153: 347-358.

102. Kondo T, Ishida Y (2010) Molecular pathology of wound healing. Forensic Sci Int 203: 93-98.

103. Godwin JW, Rosenthal N (2014) Scar-free wound healing and regeneration in amphibians: Immunological influences on regenerative success. Differentiation 87: $66-75$

104. Tisi A, Angelini R, Cona A (2008) Wound healing in plants: Cooperation of copper amine oxidase and flavin-containing polyamine oxidase. Plant Signal Behav 3: 204-246.

105. Oberpenning F, Meng J, Yoo JJ, Atala A (1999) De novo reconstitution of a functional mammalian urinary bladder by tissue engineering. Nat Biotechnol 17: 149-155.

106. Maxson S, Lopez EA, Yoo D, Danilkovitch-Miagkova A, Leroux MA (2012) Concise review: Role of mesenchymal stem cells in wound repair. Stem Cells Transl Med 1: 142-149.
107. Langer R, Vacanti JP (1993) Tissue engineering. Science 260: 920-926.

108. de Kemp V, de Graaf P, Fledderus JO, Ruud Bosch JL, de Kort LM (2015) Tissue engineering for human urethral reconstruction: Systematic review of recent literature. PLoS One 10: e0118653.

109. Fossum M, Svensson J, Kratz G, Nordenskjöld A (2007) Autologous in vitro cultured urothelium in hypospadias repair. J Pediatr Urol 3: 10-18.

110. Fossum M, Skikuniene J, Orrego A, Nordenskjöld A (2012) Prepubertal followup after hypospadias repair with autologous in vitro cultured urothelial cells. Acta Paediatr 101: 755-760.

111. Atala A, Bauer SB, Soker S, Yoo JJ, Retik AB (2006) Tissue-engineered autologous bladders for patients needing cystoplasty. Lancet 367: 1241-1246.

112. Obara T, Matsuura S, Narita S, Satoh S, Tsuchiya N, et al. (2006) Bladder acellular matrix grafting regenerates urinary bladder in the spinal cord injury rat. Urology 68: 892-897.

113. Nuininga JE, van Moerkerk $\mathrm{H}$, Hanssen A, Hulsbergen CA, Oosterwijk-Wakka $\mathrm{J}$, et al. (2004) A rabbit model to tissue engineer the bladder. Biomaterials 25 : $1657-1661$

114. Sloff M, Simaioforidis V, de Vries R, Oosterwijk E, Feitz W2 (2014) Tissue engineering of the bladder--reality or myth? A systematic review. J Urol 192 1035-1042.

115. Zhou L, Yang B, Sun C, Quu X, Sun Z, et al. (2013) Co-administration of plateletderived growth factor-BB and vascular endothelial growth factor with bladde acellular matrix enhances smooth muscle regeneration and vascularization for bladder augmentation in a rabbit model. Tissue Eng Part A 19: 264-276.

116. Youssif M, Shiina H, Urakami S, Gleason C, Nunes L, et al. (2005) Effect of vascular endothelial growth factor on regeneration of bladder acellular matrix graft: Histologic and functional evaluation. Urology 66: 201-207.

117. Chen BS, Xie H, Zhang SL, Geng HQ, Zhou JM, et al. (2011) Tissue engineering of bladder using vascular endothelial growth factor gene-modified endothelial progenitor cells. Int J Artif Organs 34: 1137-1146.

118. Chen W, Shi C, Yi S, Chen B, Zhang W, et al. (2010) Bladder regeneration by collagen scaffolds with collagen binding human basic fibroblast growth factor. J Urol 183, 2432-2439.

119. Xiong Q, Lin H, Hua X, Liu L, Sun P, et al. (2015) A nanomedicine approach to effectively inhibit contracture during bladder acellular matrix allograft-induced bladder regeneration by sustained delivery of vascular endothelial growth factor. Tissue Eng Part A 21: 45-52.

120. Loai Y, Yeger H, Coz C, Antoon R, Islam SS, et al. (2010) Bladder tissue engineering: Tissue regeneration and neovascularization of HA-VEGFincorporated bladder acellular constructs in mouse and porcine animal models. J Biomed Mater Res A 94: 1205-1215.

121. Sutherland RS, Baskin LS, Hayward SW, Cunha GR (1996) Regeneration of bladder urothelium, smooth muscle, blood vessels and nerves into an acellular tissue matrix. J Urol 156: 571-577.

122. Reddy PP, Barrieras DJ, Wilson G, Bägli DJ, McLorie GA, et al. (2000) Regeneration of functional bladder substitutes using large segment acellular matrix allografts in a porcine model. J Urol 164: 936-941. 